This document is confidential and is proprietary to the American Chemical Society and its authors. Do not copy or disclose without written permission. If you have received this item in error, notify the sender and delete all copies.

\title{
Spectroscopic and Time-Dependent DFT Study of the Photophysical Properties of Substituted 1,4- Distyrylbenzenes
}

\begin{tabular}{|r|l|}
\hline Journal: & The Journal of Physical Chemistry \\
\hline Manuscript ID & jp-2019-044922 \\
\hline Manuscript Type: & Article \\
\hline Date Submitted by the \\
Author: & 11 -May-2019 \\
\hline Complete List of Authors: & $\begin{array}{l}\text { Estrada-Flórez, Sandra; University of Ottawa, Chemistry; Universidad } \\
\text { Nacional de Colombia, Chemistry } \\
\text { Moncada, Felix; Universidad Nacional de Colombia, Departamento de } \\
\text { Química } \\
\text { Lanterna, Anabel; University of Ottawa, Centre for Advanced Materials } \\
\text { Research (CAMaR) } \\
\text { Sierra, Cesar; Universidad Nacional de Colombia, Chemistry } \\
\text { Scaiano, Juan; University of Ottawa, Chemistry }\end{array}$ \\
\hline
\end{tabular}

\section{SCHOLARONE ${ }^{\text {M }}$ Manuscripts}




\section{Spectroscopic and time-dependent DFT study of}

\section{the photophysical properties of substituted 1,4-}

\section{distyrylbenzenes}

Sandra E. Estrada-Flórez ${ }^{\alpha, \chi}$, Félix S. Moncada ${ }^{\beta, \chi}$, Anabel E. Lanterna ${ }^{\delta}$, Cesar A. Sierra ${ }^{\alpha *}$ and

Juan C. Scaiano ${ }^{\delta *}$

${ }^{\alpha}$ Grupo de Investigación en Macromoléculas, Departamento de Química, Universidad Nacional de Colombia, Bogotá-111321, Colombia

${ }^{\beta}$ Programa de Química, Universidad de la Amazonia, Calle 17 Diagonal 17 - Carrera 3F, Florencia, Colombia and Departamento de Química, Universidad Nacional de Colombia, Bogotá111321, Colombia

${ }^{\delta}$ Department of Chemistry and Biomolecular Sciences and Centre for Advanced Materials Research (CAMaR), University of Ottawa, 10 Marie Curie, Ottawa, Ontario K1N 6N5, Canada 


\begin{abstract}
In this contribution we examine the photophysical properties of fifteen totally trans-trans 1,4-distyrylbenzene derivatives (DSBs) functionalized with different electrondonating (ED) and electron-withdrawing (EW) groups by experimental and computational methodologies. We use UV-Vis and fluorescence spectroscopy to determine the experimental optical properties such as the maximum absorption $\left(\lambda_{a b s}^{\exp }\right)$ and emission $\left(\lambda_{e m}^{\exp }\right)$ wavelengths, the HOMO-LUMO energy gaps $\left(\Delta \mathrm{E}_{a b s}^{e x p}\right)$, the molar extinction coefficients $(\varepsilon)$, the fluorescence quantum yields $\left(\Phi_{f}\right)$ and the fluorescence lifetimes $(\tau)$. We also calculate the experimental oscillator strengths $\left(F_{o s c}^{\text {exp }}\right)$ and spontaneous emission decay rate $\left(k_{r}^{\text {exp }}\right)$ and correlate all these magnitudes to the corresponding calculated properties - maximum absorption $\left(\lambda_{a b s}^{c a l}\right)$ and emission $\left(\lambda_{e m}^{c a l}\right)$ wavelengths, vertical transition energies $\left(\Delta \mathrm{E}_{a b s}^{c a l}\right)$, oscillator strength $\left(F_{o s c}^{c a l}\right)$ and spontaneous emission decay rate $\left(k_{r}^{c a l}\right)$ - obtained by the TDDFT method. We analyze the effect of the electronic nature of the substituents on the properties of the DSBs, finding that the ED and EW groups lead to bathochromic shifts. This is consistent with the decrease of $\Delta \mathrm{E}$ values as the strength of ED and EW substituents increases. We find excellent correlations between calculated and experimental values for $\lambda_{a b s}, \lambda_{e m}$ and $\Delta \mathrm{E}_{a b s}(\mathrm{r} \sim 0.99-0.95)$. Additionally, $F_{\mathrm{osc}}$ and $k_{\mathrm{r}}$ values are in good agreement $(\mathrm{r} \sim 0.87-0.72)$ with the experimental properties. Overall, we find that for substituted 1,4-DSBs, computational chemistry is an excellent tool to predict structure-property relationships, which can be useful to forecast the properties of their polymeric analogs, which are usually difficult to determine experimentally.
\end{abstract}

\title{
1. Introduction
}

Poly(phenylenevinylene) (PPV) and its derivatives have attracted considerable attention because of their remarkable optical and electronic properties. It is well known that after the discovery of 
the optoelectronic properties of PPVs, especially the electroluminescence ${ }^{1-2}$, these materials have been exploited as an active layer in organic light-emitting diodes (OLEDs) $)^{3-13}$ and other applications such as laser dyes ${ }^{14-16}$, photovoltaic cells $s^{17-23}$, chemosensors ${ }^{24-29}$, linkers for metalorganic frameworks (MOFs) $)^{30-32}$, dendrimers ${ }^{33-36}$, photoredox catalysts and photosensitizers ${ }^{37-39}$. The synthesis of PPVs frequently presents challenges as it leads to a mixed cis/trans configuration over the vinyl segments of the polymeric structure; they show large dimensions and poor solubility in a wide range of solvents. ${ }^{40}$

Oligo(phenylenevinylene)s (OPVs) have drawn interest as structural models for PPVs, as their synthesis yields well-defined chemical structures that allow for easier optoelectronic characterizations. OPVs share many properties with their structural analog PPVs, especially in the case of segmented polymers. This is useful to determine which structural features of a PPV, or a segmented polymer, are the most appropriate to incorporate for a given application. This is known as "the oligomer approach"41. The OPVs smaller size allows computational studies of their optoelectronic properties with state-of-the-art density functional theory (DFT) methods that complement the experimental information.

Perhaps the most studied OPVs are distyrylbenzene (DSBs) derivatives. The optoelectronic properties of numerous substituted DSBs have been investigated by both experimental ${ }^{42-49}$ and computational methods ${ }^{50-55}$. With the goal of understanding the structure-property relationships of these technological attractive materials, we reported the synthesis of a full trans-trans DSBs series with different electron-donor (ED) and electron-withdrawing (EW) substituents by Mizoroki-Heck cross-coupling reactions ${ }^{56}$. The interest in the trans-configuration of the vinyl bonds reflects that a more-planar conformation is obtained, which facilitates conjugation and improves their optical and electronic properties ${ }^{57-58}$. 
The study of the structural effects on the photophysical properties of DSBs provides insights into the structural features that a phenylenevinylene derivative (oligomer or polymer) must have to be useful. Thus, in order to understand better the structure-property relationships of this type of materials, here we correlate the experimental optical characterization of DSBs - substituted with different ED or EW groups (Figure 1) - with their optical properties calculated by computational methods based on the time-dependent DFT (TDDFT).

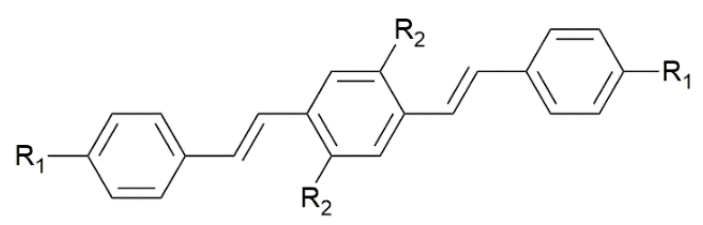

\begin{tabular}{|c|c|c|c|c|c|}
\hline \multicolumn{3}{|c|}{ Series 1} & \multicolumn{3}{|c|}{ Series 2} \\
\hline DSB & $\mathrm{R}_{1}$ & $\mathrm{R}_{2}$ & DSB & $\mathrm{R}_{1}$ & $\mathrm{R}_{2}$ \\
\hline 1-H-DSB & $-H$ & $-\mathrm{H}$ & 2-H-DSB & $-\mathrm{H}$ & $-\mathrm{OCH}_{3}$ \\
\hline 1-OH-DSB & $-\mathrm{OH}$ & $-\mathrm{H}$ & 2-OH-DSB & $-\mathrm{OH}$ & $-\mathrm{OCH}_{3}$ \\
\hline 1-OMe-DSB & $-\mathrm{OCH}_{3}$ & $-\mathrm{H}$ & 2-OMe-DSB & $-\mathrm{OCH}_{3}$ & $-\mathrm{OCH}_{3}$ \\
\hline 1-OCOMe-DSB & $-\mathrm{OCOCH}_{3}$ & $-\mathrm{H}$ & 2-OCOMe-DSB & $-\mathrm{OCOCH}_{3}$ & $-\mathrm{OCH}_{3}$ \\
\hline 1-CN-DSB & $-\mathrm{CN}$ & $-\mathrm{H}$ & 2-CN-DSB & $-\mathrm{CN}$ & $-\mathrm{OCH}_{3}$ \\
\hline $1-\mathrm{NO}_{2}-\mathrm{DSB}$ & $-\mathrm{NO}_{2}$ & $-\mathrm{H}$ & $2-\mathrm{NO}_{2}-\mathrm{DSB}$ & $-\mathrm{NO}_{2}$ & $-\mathrm{OCH}_{3}$ \\
\hline 1-CoOMe-DSB & $-\mathrm{COOCH}_{3}$ & $-\mathrm{H}$ & 2-Me-DSB & $-\mathrm{CH}_{3}$ & $-\mathrm{OCH}_{3}$ \\
\hline 1-COMe-DSB & $-\mathrm{COCH}_{3}$ & $-\mathrm{H}$ & & & \\
\hline
\end{tabular}

Figure 1. Chemical structure of the studied DSBs.

\section{Experimental section}

\subsection{Materials}

The trans-trans 1,4-distyrylbenzene derivatives (DSBs) were previously synthesized by the Mizoroki-Heck cross-coupling reaction and the synthetic protocols are described in the literature ${ }^{56}$. The solvent used for the optical characterization $\left(\mathrm{CHCl}_{3}\right)$ was purchased from Fisher Scientific and used without further purification.

\subsection{Experimental procedures}

DSBs compounds were dissolved in $\mathrm{CHCl}_{3}$ to prepare $10 \mu \mathrm{M}$ solutions. In order to obtain the 
desired concentrations for compounds with poor solubility (e.g., Series 1) ultrasonic and heating techniques were applied. UV-vis spectra were measured on an Agilent Cary 60 spectrophotometer. The experimental HOMO-LUMO energy gaps $\left(\Delta \mathrm{E}_{a b s}^{e x p}\right)$ were determined from the analysis of the absorption edge according to equation 1 :

$$
\alpha \cdot h v=A \cdot(h v-\Delta \mathrm{E})^{1 / 2}
$$

where $\alpha$ is the absorption coefficient, $h$ is the Planck constant, $v$ is the frequency of light and $A$ is the absorbance. By plotting $(h v A)^{2} v s . h v$, and extending the linearity edge of absorbance to the intersect with the energy axis the $\Delta \mathrm{E}$ value can be obtained $\mathrm{d}^{59-60}$. The molar extinction coefficients (ع) were obtained from the slopes in the absorbance $v s$. concentration plots. To calculate the experimental oscillator strengths $\left(F_{\mathrm{osc}}^{\exp }\right)$ we performed least squares fittings of the absorption spectra expressed in wavenumbers to linear combinations of Gaussian-type functions. The $F_{\mathrm{osc}}^{\text {exp }}$ are related to the area under the absorption spectra and for Gaussian shaped bands are calculated $\mathrm{as}^{61}$ :

$$
F_{\text {osc }}^{\text {exp }}=4.67 \cdot 10^{-9} \frac{\mathrm{mol} \mathrm{cm}^{2}}{L} \varepsilon_{\max } \Delta \tilde{\mathrm{v}}_{1 / 2},
$$

where $\Delta \tilde{\mathrm{v}}_{1 / 2}$ is the band full width at half maximum (FWHM) value in $\mathrm{cm}^{-1}$.

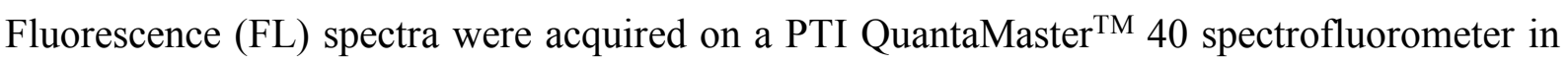
$\mathrm{CHCl}_{3}$ solutions. The fluorescence quantum yields $\left(\Phi_{f}\right)$ were determined at $\lambda_{\text {exc }}$ corresponding to the absorption maxima. Quinine sulfate in $0.1 \mathrm{M} \mathrm{H}_{2} \mathrm{SO}_{4}\left(\Phi_{f}=0.54\right)$ was used as the standard for determination of fluorescence quantum yields $\left(\Phi_{f}\right)$ at $\lambda_{\text {exc }}$ corresponding to the absorption maximum of series 1. Perylene in ethanol $\left(\Phi_{f}=0.92\right)$ was used as the standard for determination of the $\Phi_{f}$ at $\lambda_{\text {exc }}$ corresponding to the second absorption maximum of series $2\left(\lambda_{2}\right)$. The $\Phi_{f}$ of 1- 
NO2-DSB was calculated also using perylene as standard. The $\Phi_{f}$ values were calculated according to a method described in the literature ${ }^{62}$, using equation 3 :

$$
\Phi_{f(\mathrm{DSB})}=\Phi_{f(\mathrm{ST})} \frac{f_{(\mathrm{ST})}}{f_{(\mathrm{DSB})}} \frac{F_{(\mathrm{DSB})}}{F_{(\mathrm{ST})}}\left(\frac{\eta_{(\mathrm{DSB})}}{\eta_{(\mathrm{ST})}}\right)^{2}
$$

where $\Phi_{f(\mathrm{DSB})}$ and $\Phi_{f(\mathrm{ST})}$ are the fluorescence quantum yield of the sample and the standard, respectively. $f_{(\mathrm{DSB})}$ and $f_{(\mathrm{ST})}$ are the absorption factors, that is the fraction of the light impinging on the sample that is absorbed: $f_{(\mathrm{DSB})}=1-10^{-\mathrm{A}(\mathrm{DSB})}$ and $f_{(\mathrm{ST})}=1-10^{-\mathrm{A}(\mathrm{ST})} \cdot F_{(\mathrm{DSB})}$ y $F_{(\mathrm{ST})}$ are the integrated intensities (areas under the emission curve) of the sample and standard spectra, respectively. $\eta_{(\mathrm{DSB})} \mathrm{y} \eta_{(\mathrm{ST})}$ are the refractive indices of the solvent used in the sample and reference solutions, respectively. The fluorescence lifetimes $(\tau)$ were measured in an Easy-Life (PTI) system with samples with a maximum absorbance of 0.1 (at the excitation wavelength) in $\mathrm{CHCl}_{3}$ under nitrogen atmosphere. Since it is possible to relate the radiative and non-radiative constants $\left(k_{r}\right.$ and $\left.k_{n r}\right)$ with the $\Phi_{f}$ and $\tau$ values $^{63}$,

$$
\begin{gathered}
\Phi_{f}=\frac{k_{r}}{k_{r}+k_{n r}} \\
\tau=\frac{1}{k_{r}+k_{n r}}
\end{gathered}
$$

the experimental radiative constants $\left(k_{r}^{e x p}\right)$ were calculated from equation 6 :

$$
k_{r}^{\exp }=\frac{\Phi_{f}}{\tau}
$$

\section{Computational calculations}

The ground and first excited state geometries of the 15 DSBs were optimized the CAM-B3LYP functional ${ }^{64}$ and the def2-TZVPP ${ }^{65-66}$ basis set considering $\mathrm{CHCl}_{3}$ as the solvent with the conductor-like polarizable continuum model ${ }^{67}$. For all molecules, the initial geometry was built 
with the $\mathrm{C}_{2 \mathrm{~h}}$ symmetry point group. All calculations were performed with the ORCA computational package ${ }^{68}$ with the resolution of identity and chain of spheres approximations ${ }^{69}$. All TDDFT calculations employed the Tamm-Dancoff approximation ${ }^{70}$.

Eight vertical transition energies $\left(\Delta \mathrm{E}_{a b s}^{c a l}\right.$ and $\left.\Delta \mathrm{E}_{e m}^{c a l}\right)$ and oscillator strengths $\left(\Delta \mathrm{F}_{o s c}^{c a l}\right)$ were obtained from single-point TDDFT calculations at the ground and excited state equilibrium geometries. The maximum absorption $\left(\lambda_{a b s}^{c a l}\right)$ and emission $\left(\lambda_{e m}^{c a l}\right)$ wavelengths were calculated from the $\Delta \mathrm{E}_{a b s}^{c a l}$ and $\Delta \mathrm{E}_{e m}^{c a l}$ values as $\lambda=h c / \Delta \mathrm{E}$, where $c$ is the speed of light.

The calculated radiative constants $\left(k_{r}^{c a l}\right)$ from excited to ground state were calculated according to:

$$
k_{r}^{c a l}=\frac{4}{3} \frac{\left(\Delta \mathrm{E}_{e m}^{c a l}\right)^{3}}{c^{3}} \mu_{10}^{2}
$$

where $\mu_{10}$ is the transition dipole strength evaluated at the excited state geometry ${ }^{71}$.

\section{Results and discussion}

The 1,4-distyrylbenzenes synthesized by Mizoroki-Heck cross-coupling reaction were obtained as total trans-configuration systems ${ }^{56}$. The UV-vis spectroscopic characterization of these compounds is shown in Figure 2. The absorption spectra of the DSBs of series 1 (Figure 2a) present a maximum absorption band due to $\pi \rightarrow \pi^{*}$ electronic transitions, while the absorption spectra of the DSBs of series 2 (Figure 2b), which have methoxy groups in the central ring, exhibit two maximum absorption bands, one of higher energy and lower intensity assigned to the $n \rightarrow \pi^{*}$ transition, and one of lower energy and higher intensity due to the $\pi \rightarrow \pi^{*}$ transitions of the DSB systems. 


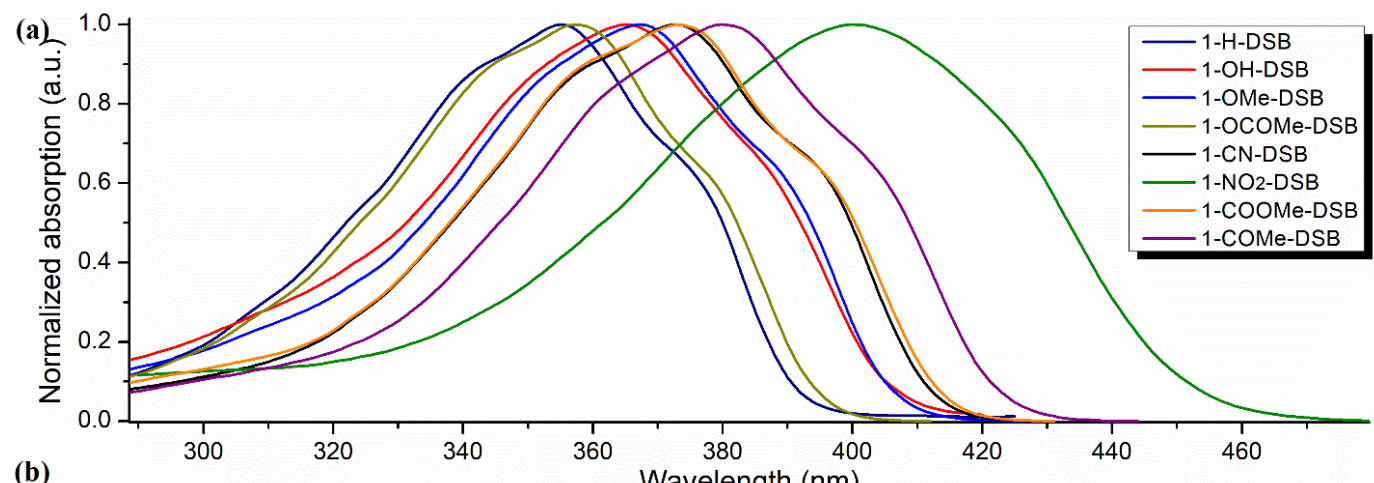

(b)

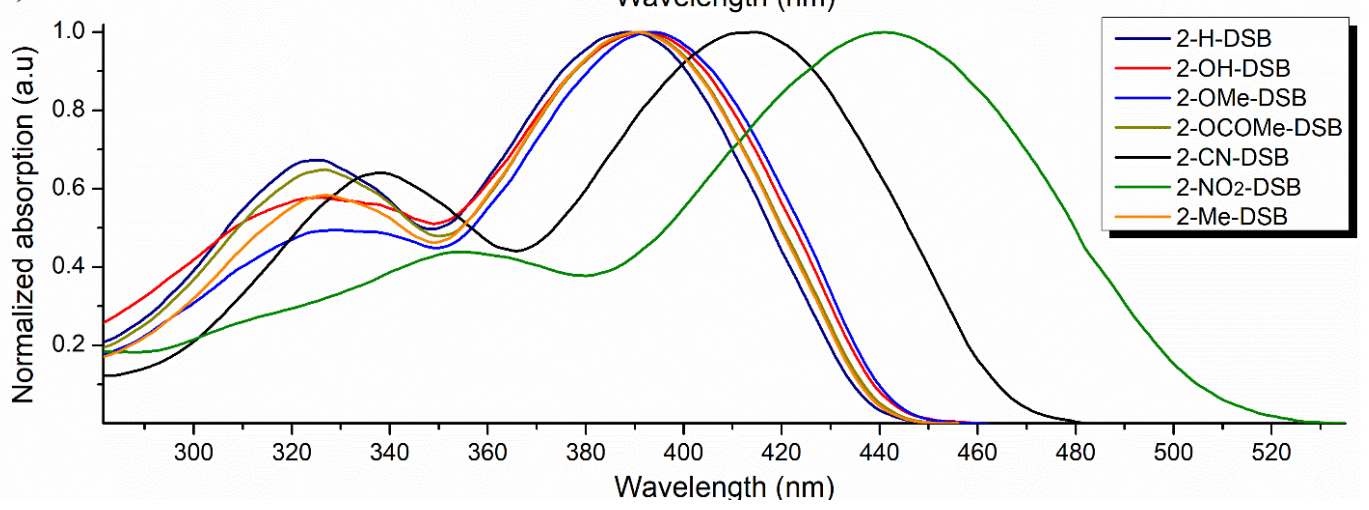

Figure 2. Normalized absorption spectra of DSBs of (a) series 1 and (b) series 2 measured in $\mathrm{CHCl}_{3}$.

The calculated electronic transitions are presented in Tables S6 and S7 in the supporting information. Series 1 molecules only show strong $\mathrm{S}_{0 \rightarrow 1}$ transitions $\left(\lambda_{a b s}^{c a l}=331\right.$ to $\left.374 \mathrm{~nm}\right)$, whereas Series 1 molecules show strong $\mathrm{S}_{0 \rightarrow 1}$ transitions, $\left(\lambda_{a b s}^{c a l}=364\right.$ to $\left.415 \mathrm{~nm}\right)$ and less intense $\mathrm{S}_{0 \rightarrow 2}$ transitions $\left(\lambda_{a b s}^{c a l}=293\right.$ to $\left.322 \mathrm{~nm}\right)$, in good agreement with the experimental observations. The orbital pair contributions presented in Table $\mathrm{S} 8$ show that the most important contribution to $\mathrm{S}_{0 \rightarrow 1}$ transition comes from the HOMO-LUMO excitations, as the TDDFT combination coefficient of these orbitals is larger than 0.9 in all cases.

Figure 3 shows a comparison of the experimental absorption properties for DBSs of series 1 in $\mathrm{CHCl}_{3}$ obtained by UV-vis spectroscopy with the calculated by TDDFT. To facilitate understanding, the order of substituents in the figures was established according to the reported Hammett substituent constants $\left(\sigma_{p}\right)^{72}$, which show how electron-donating or electron-withdrawing 
a group is relative to a neutral group $(\mathrm{H})$ in the para position of the aromatic terminal rings of the DSBs. The experimental and calculated data are shown in the SI file (Table S1).

Figures $3 \mathrm{a}, 3 \mathrm{~b}$ and $3 \mathrm{c}$ show the comparison between $\lambda_{a b s}^{\text {exp }}$ and $\lambda_{a b s}^{c a l}, \Delta \mathrm{E}_{a b s}^{\text {exp }}$ (calculated by eq. 1) and $\Delta \mathrm{E}_{a b s}^{c a l}$, and $F_{\text {osc }}^{e x p}$ (calculated by eq. 2) and $F_{\text {OSC }}^{c a l c}$, respectively, all as a function of the corresponding $\sigma_{p}$ values. This figure shows that the computational studies describe very well the optical properties of these molecules. Likewise, Figure 4 shows the results obtained for series 2 DSBs. Figure 4a shows the comparison between $\lambda_{a b s}^{\text {exp }}$ and $\lambda_{a b s}^{\text {calc }}$ determined at the two maximum absorption bands $\left(\lambda_{1}\right.$ and $\left.\lambda_{2}\right)$, figure $4 \mathrm{~b}$ compares the $\Delta \mathrm{E}_{a b s}^{\text {exp }}$ and $\Delta \mathrm{E}_{a b s}^{c a l}$ values for the second absorption maximum $\left(\lambda_{2}\right)$, and figure $4 \mathrm{c}$ compares $F_{\text {osc }}^{\text {exp }}$ (calculated by eq. 2 ) and $F_{\text {osc }}^{\text {calc }}$ determined at $\lambda_{1}$ and $\lambda_{2}$. 

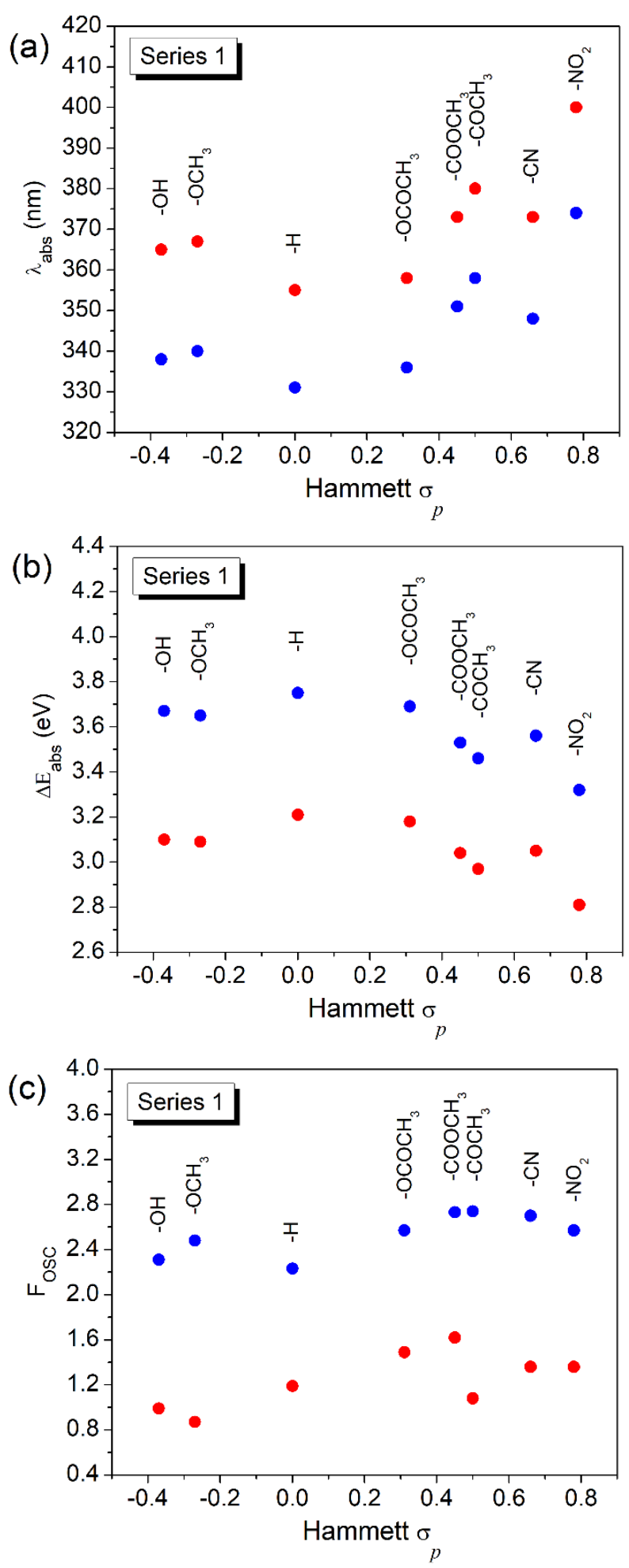

Figure 3. Experimental data (red) and computational calculations (blue) for the optical properties of DSBs-series 1 in $\mathrm{CHCl}_{3}$ as a function of $\sigma_{p}$ : (a) $\lambda_{\text {abs }}$ (b) $\Delta \mathrm{E}_{\text {abs }}$ (c) $F_{\text {osc. }}$. 

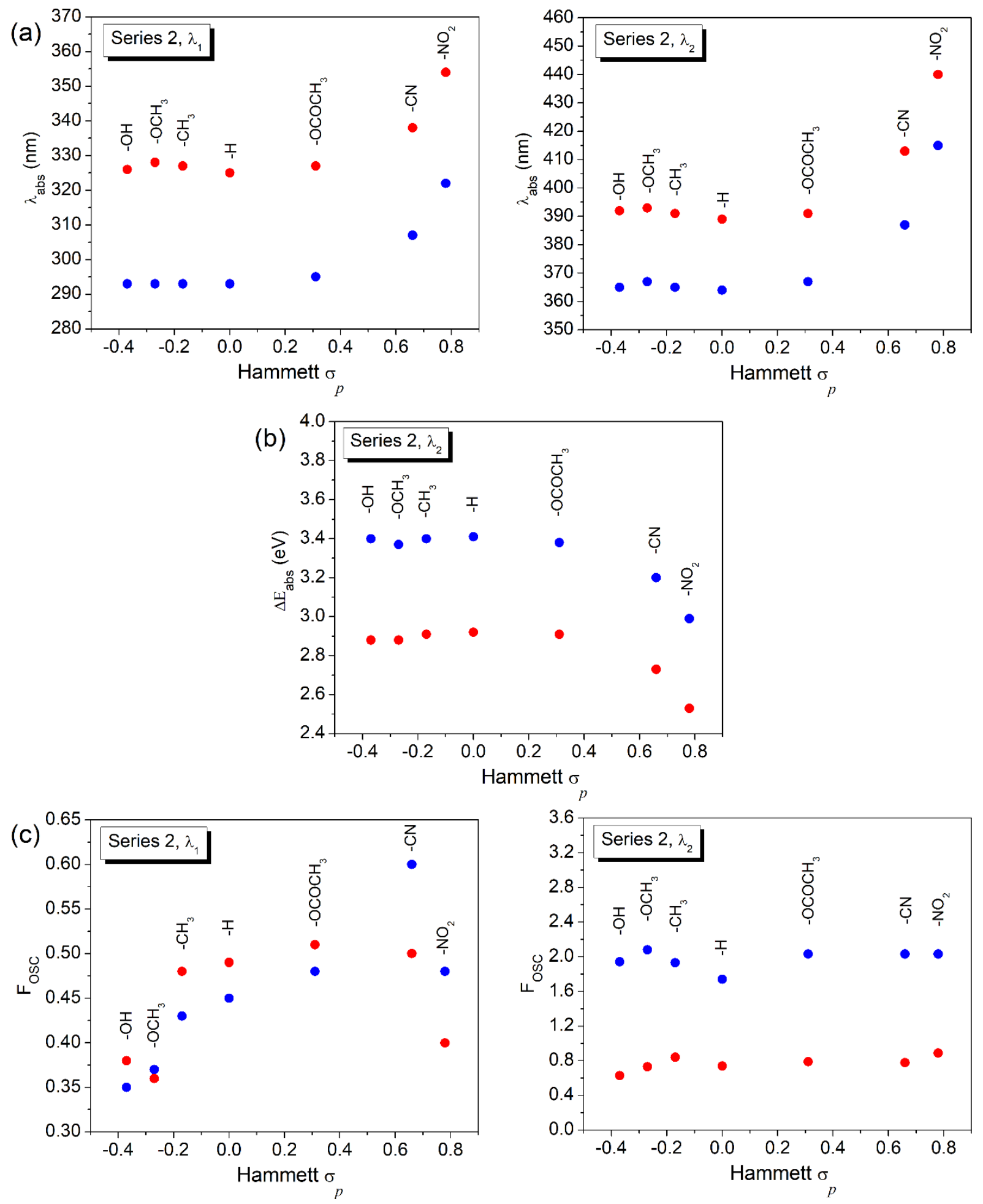

Figure 4. Experimental data (red) and computational calculations (blue) for the absorption properties of DSBs-series 2 in $\mathrm{CHCl}_{3}$ as a function of $\sigma_{p}$ : (a) $\lambda_{\text {abs }}$ (b) $\Delta \mathrm{E}_{\text {abs }}$ (c) $F_{\text {osc }}$. 
Results in Figures 3 and 4, along with the spectra shown in Figure 2, show that in $\mathrm{CHCl}_{3}$ both ED and EW groups at the two ends of the DSB structure lead to bathochromic shifts of the absorption band compared to the unsubstituted DSBs (1-H-DSB and 2-H-DBS). In particular, the ED groups studied have a moderate effect on the bathochromic shift $(\Delta \mathrm{A} \sim 10 \mathrm{~nm})$, whereas EW groups have a greater effect $(\Delta \mathrm{A}>20 \mathrm{~nm})$; that is, greater shifts are found when the electron donating or electron withdrawing strength of the substituent increases. A similar trend has been reported in other studies of DSBs with ED and/or EW substituents on the terminal rings ${ }^{44-46}$. Although the absorption band shift caused by the ED and EW substituents seems to be smaller in DSBs of series 2, compared to series 1, it is important to note that the entire absorption spectrum for each of the DSBs of series 2 is red shifted, indicating that the presence of two ED substituents (methoxy groups) over the central ring strongly affect the optical properties of DSBs. Comparing the reference compounds in each series, the methoxy groups in the central ring of the 2-H-DSB produce a large bathochromic shift $(\sim 34 \mathrm{~nm})$ with respect to its unsubstituted 1-H-DSB counterpart similar to computational predictions $(\sim 32 \mathrm{~nm})$. A similar study reported by Chaieb et al., also showed that the introduction of ED groups on the central ring of the DSB system leads to a red shift $^{45}$.

Results in Figures 3 and 4 also show that the EW groups in the DSB system lead to smaller HOMO-LUMO energy gaps $(\Delta \mathrm{E})$, being lowest for 1-NO $-\mathbf{D S B}$ and 2-NO2-DSB. The ED groups also contribute to decreasing the $\Delta \mathrm{E}$ with respect to unsubstituted DSBs. The trend shows that $\Delta \mathrm{E}$ decreases with the strength of ED and EW substituents, in agreement with the increased bathochromic shift. A similar trend in the decrease of $\Delta \mathrm{E}$ values with ED groups was found by Wu and coworkers ${ }^{44}$, who reported optical properties of DSBs substituted with other ED such as $-\mathrm{CH}_{3}$, $-\mathrm{C}\left(\mathrm{CH}_{3}\right)_{3},-\mathrm{O}\left(\mathrm{CH}_{2}\right)_{4} \mathrm{CH}_{3},-\mathrm{N}\left(\mathrm{CH}_{3}\right)_{2}$. Additionally, we probed that $\mathrm{EW}$ groups such as $-\mathrm{COOCH}_{3}$, 
$-\mathrm{COCH}_{3},-\mathrm{CN}$ and $-\mathrm{NO}_{2}$ follow the same trend with an intensified effect on the decrease of $\Delta \mathrm{E}$ values. On the other hand, the $\Delta \mathrm{E}$ values obtained for DSBs of series 2 are lower than those obtained for DSBs of series 1, which indicate that the introduction of methoxy groups in the central ring favors a decrease in the energy gap.

In order to understand how the different substituents affect the optical properties of the DSB, we calculate the orbital eigenvalues for the DSB series 1 and series 2 (Figure 5). The results reveal that, relative to unsubstituted DSBs, EW groups decrease the energies of both HOMO and LUMO, but the effect on the latter is larger. On the other hand, ED groups increase the HOMO and LUMO energies, and they have a larger impact on the HOMO. For both EW and ED groups, these changes in orbital energies lead to a HOMO-LUMO energy gap shrinkage and therefore to the bathochromic shifts observed in the UV-vis spectra.

Figure 5 also displays the electron density changes that occur upon excitation in the DSBs of series 1 and 2. For all molecules, the changes in the central aromatic ring and the connecting vinyl units are similar, with alternating density increases and decreases between bonds. In DSBs with ED groups, the electron density around the oxygen atom decreases upon excitation, whereas in DSBs with EW groups, the density around the $-\mathrm{NO}_{2},-\mathrm{CN}$ and carbonyl moieties increase upon excitation. 

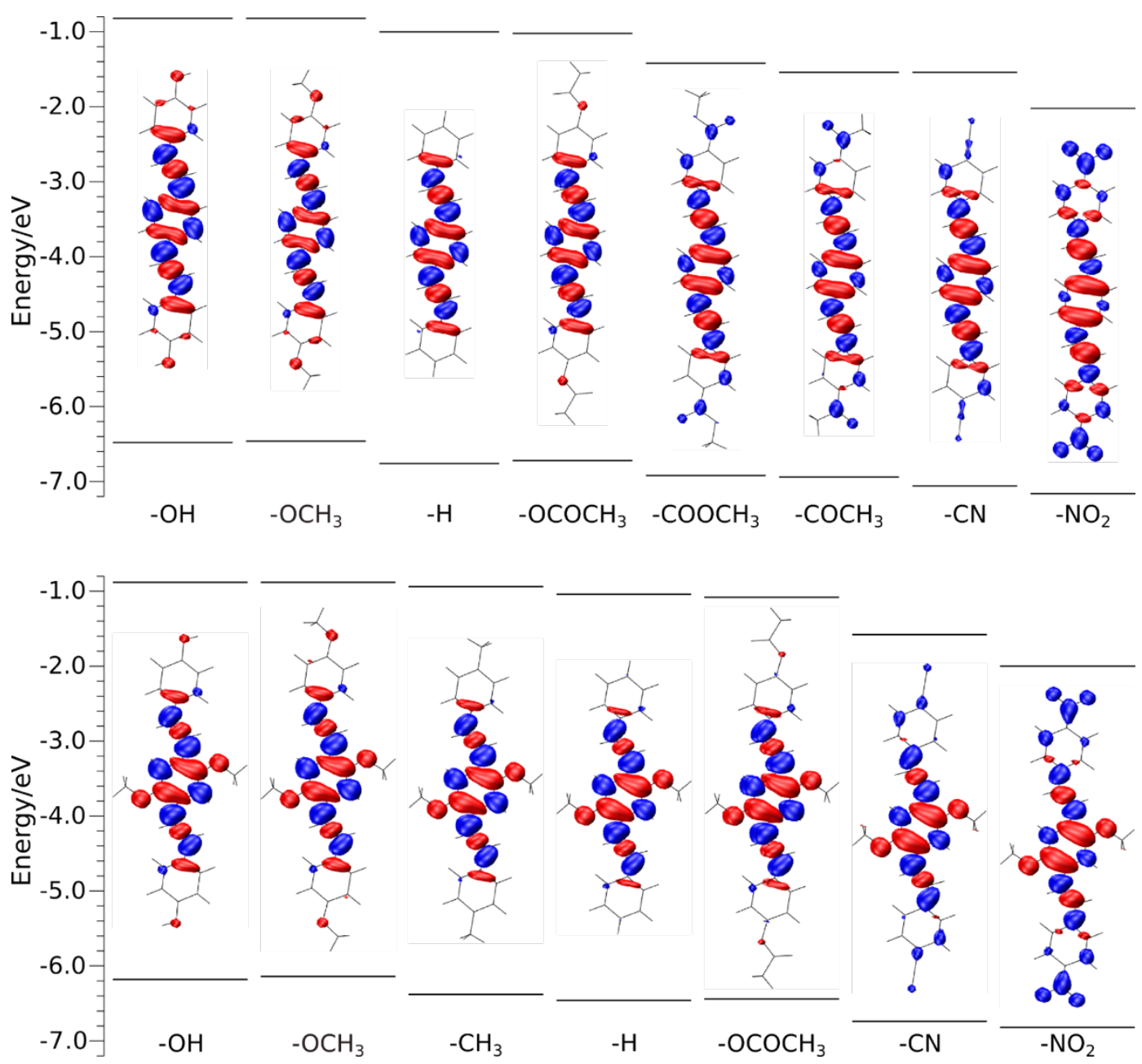

Figure 5: Calculated HOMO-LUMO eigenvalues and electron density changes upon excitation $\left(\mathrm{S}_{0} \rightarrow \mathrm{S}_{1}\right)$ for the DSBs of series 1 (top) and series 2 (bottom). Blue electron density contours are drawn at 0.001 a.u. and red contours at -0.001 a.u.

Regarding the molar extinction coefficient $(\varepsilon)$, no clear trends were observed (see Tables S1S2). DSBs of series 1 showed values of $\varepsilon$ higher than those obtained for DSBs of series 2 . Consequently, the experimental oscillator strength $\left(F_{\text {osc }}^{\exp }\right)$, obtained from equation 2 , shows higher values for DSBs of series 1 - ranging from 0.87 to 1.62 - and lower values for DSBs of series 2 from 0.36 to 0.51 at $\lambda_{1}$ and from 0.63 to 0.89 at $\lambda_{2}$. The same behavior was predicted by computational calculations, where DSBs of series 1 showed values of $F_{\text {osc }}^{c a l}$ higher than those obtained for DSBs of series 2. For DSBs of series 1 the $F_{\mathrm{osc}}^{c a l}$ ranges from 2.23 to 2.74. In addition, 
the $F_{\text {osc }}^{c a l}$ values for series 2 are higher for the first transition $\left(\lambda_{2}\right)$, which is the most intense, ranging from 1.74 to 2.08 , whereas for the second transition $\left(\lambda_{1}\right)$ this quantity ranges from 0.35 to 0.60 .

The results shown above demonstrate that the computational calculations can be used to predict the optical properties of DSBs. In order to support this, we correlate the results obtained from the computational and experimental absorption properties studied for the DSBs of series 1 and 2 (Figure 6). In Figure 6a, which shows the correlation between $\lambda_{a b s}^{c a l}$ and $\lambda_{a b s}^{\text {exp }}$ values, the DFT results predict maximum absorption wavelengths that are about $20 \mathrm{~nm}$ smaller than the experimental values, but with a high correlation $(r=0.996)$. In figure $6 \mathrm{~b}$ one can see the correlation between $\Delta \mathrm{E}_{a b s}^{c a l}$ and $\Delta \mathrm{E}_{a b s}^{e x p}$ values. Again, DFT predicts values that, on average, are $0.50 \mathrm{eV}$ higher than the experimental values, with excellent correlation $(r=0.993)$. It was observed that the computational method correctly predicts that the energy gaps for DSBs of series 1 are larger than those for DSBs of series 2. Finally, figure $6 \mathrm{c}$ shows the correlation of the experimental $F_{\text {osc }}^{\text {exp }}$ values (calculated by eq. 2) as a function of the calculated $F_{\text {osc }}^{c a l}$ values. In this case, although the correlation is $\operatorname{good}(\mathrm{r}=0.87)$, it is not ideal for quantitative predictions. Nevertheless, the computational method correctly clusters the transitions of DSBs of series 1 as the most intense and the second transitions of DSBs of series 2 as the least. 

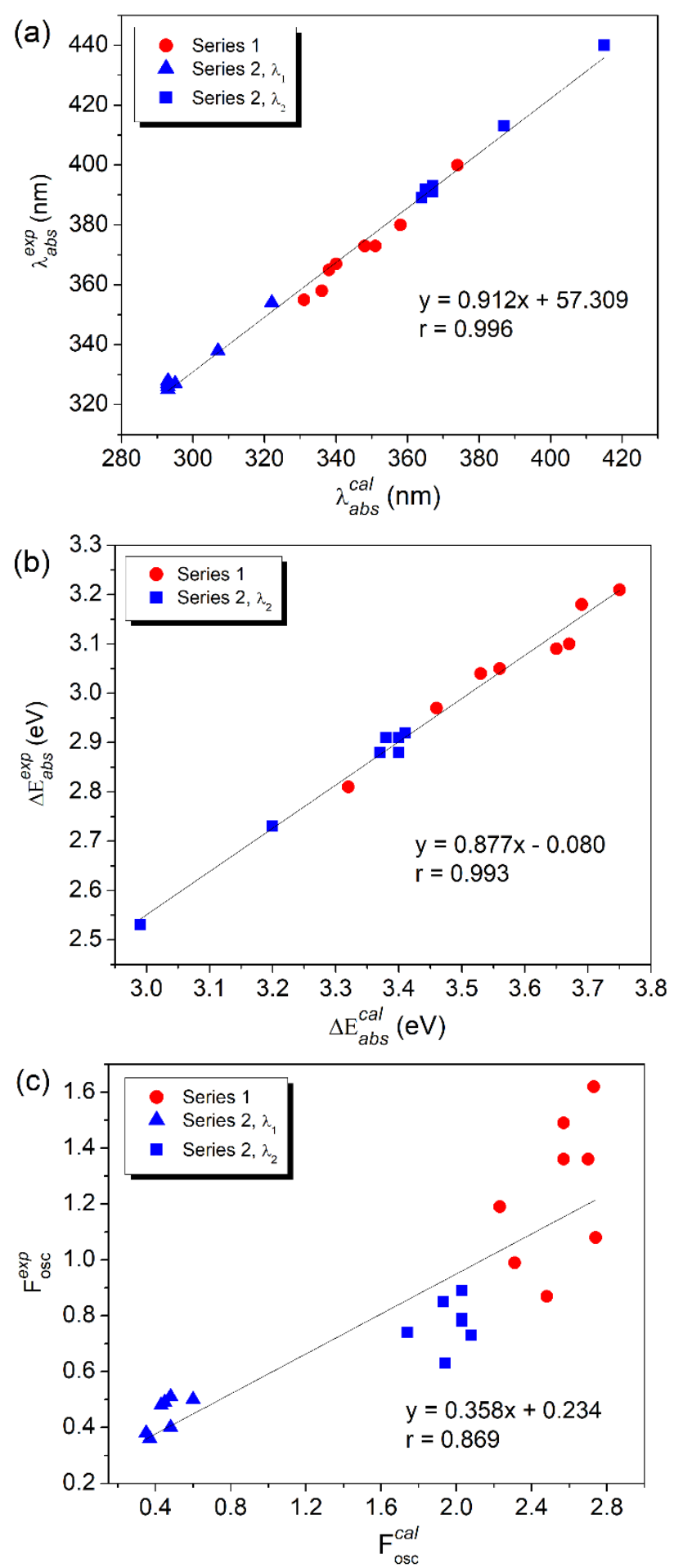

Figure 6: Correlation between the experimental and calculated absorption properties (a) $\lambda_{a b s}^{\exp }$ and $\lambda_{a b s}^{c a l}$, (b) $\Delta \mathrm{E}_{a b s}^{e x p}$ and $\Delta \mathrm{E}_{a b s}^{c a l}$, and (c) $F_{\mathrm{osc}}^{\text {exp }}$ and $F_{\mathrm{osc}}^{c a l}$. Red circles: DSBs of series 1. Blue triangles: DSBs of series $2\left(\lambda_{1}\right)$. Blue squares: DSBs of series $2\left(\lambda_{2}\right)$. 
Next, we analyze the emission properties of the DSBs using FL spectroscopy and TDDFT calculations. The normalized emission spectra of the DSBs of series 1 and 2 are shown in Figure $7 \mathrm{a}$ and $7 \mathrm{~b}$, respectively.
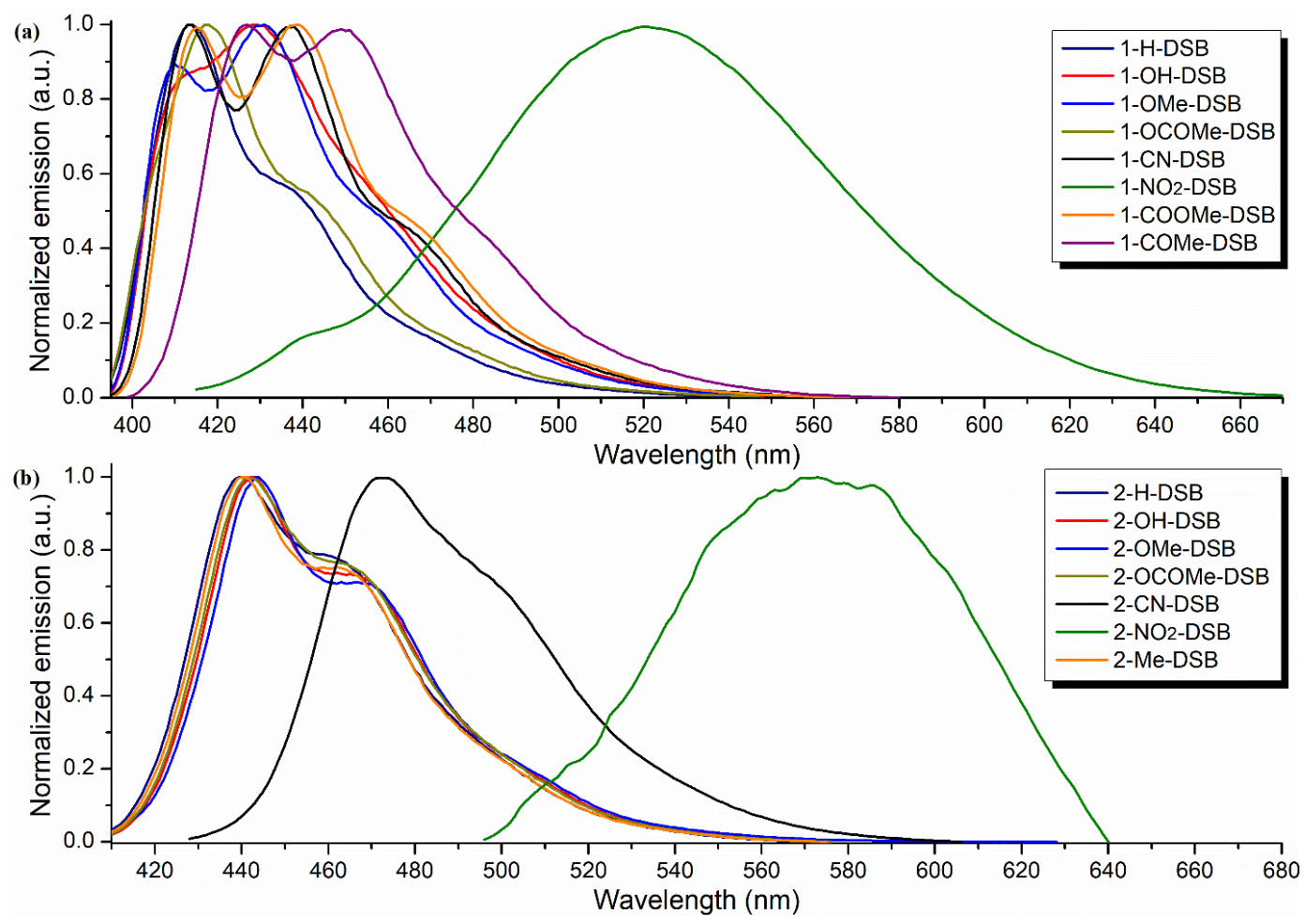

Figure 7. Normalized emission spectra of the DSBs of (a) series 1, and (b) series 2, measured in $\mathrm{CHCl}_{3}$.

Figure 8 shows a comparison of the experimental emission properties for DBSs of series 1 in $\mathrm{CHCl}_{3}$ obtained by $\mathrm{FL}$ spectroscopy with the calculated by TDDFT. Figure 8a compares the experimental and calculated maximum emission wavelengths $\left(\lambda_{\mathrm{em}}\right)$, and Figure $8 \mathrm{~b}$ the experimental (determined by eq. 6) and calculated spontaneous emission decay rates $\left(k_{r}\right)$. As it is shown in Figures 3 and 4, the order of substituents in the figures was established according to the corresponding $\sigma_{p}$ values. Furthermore, Figure 9 shows the comparison between $\lambda_{e m}^{\text {exp }}$ and $\lambda_{\text {em }}^{c a l}$, and between $k_{r}^{\text {exp }}$ and $k_{r}^{c a l}$ values for DBSs of series 2 in $\mathrm{CHCl}_{3}$. 

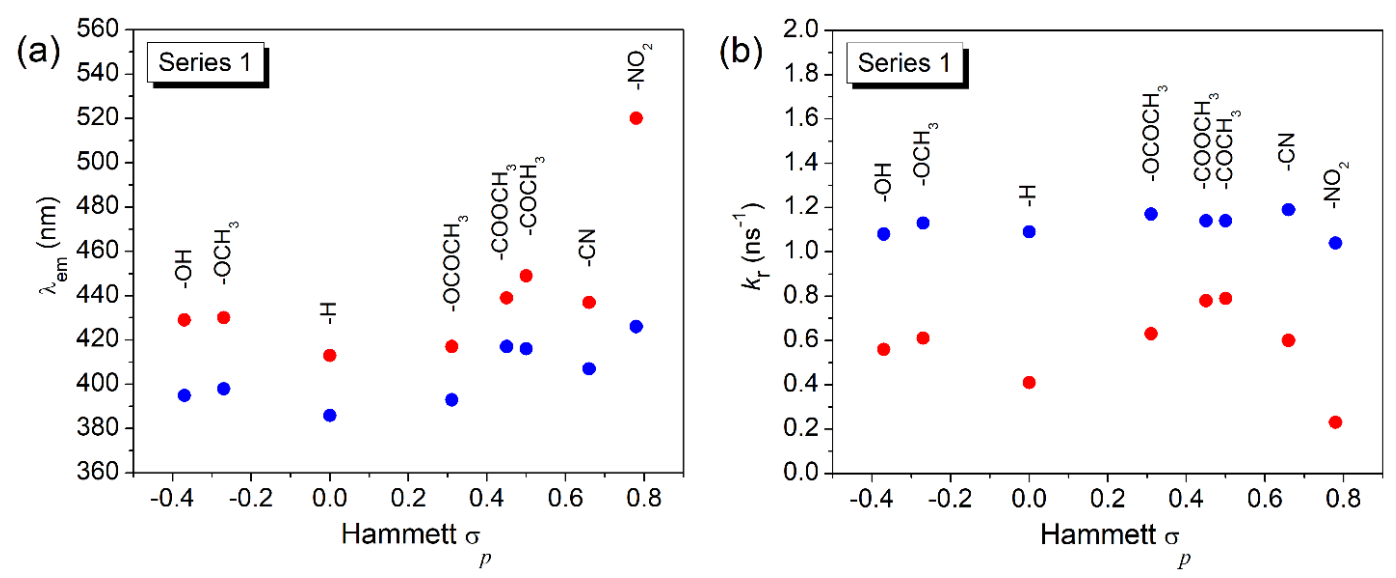

Figure 8. Experimental data (red) and computational calculations (blue) for the emission properties of DSBs-series 1 in $\mathrm{CHCl}_{3}$ as a function of the corresponding $\sigma_{p}$ : (a) $\lambda_{\mathrm{em}}$ (b) $k_{\mathrm{r}}$.
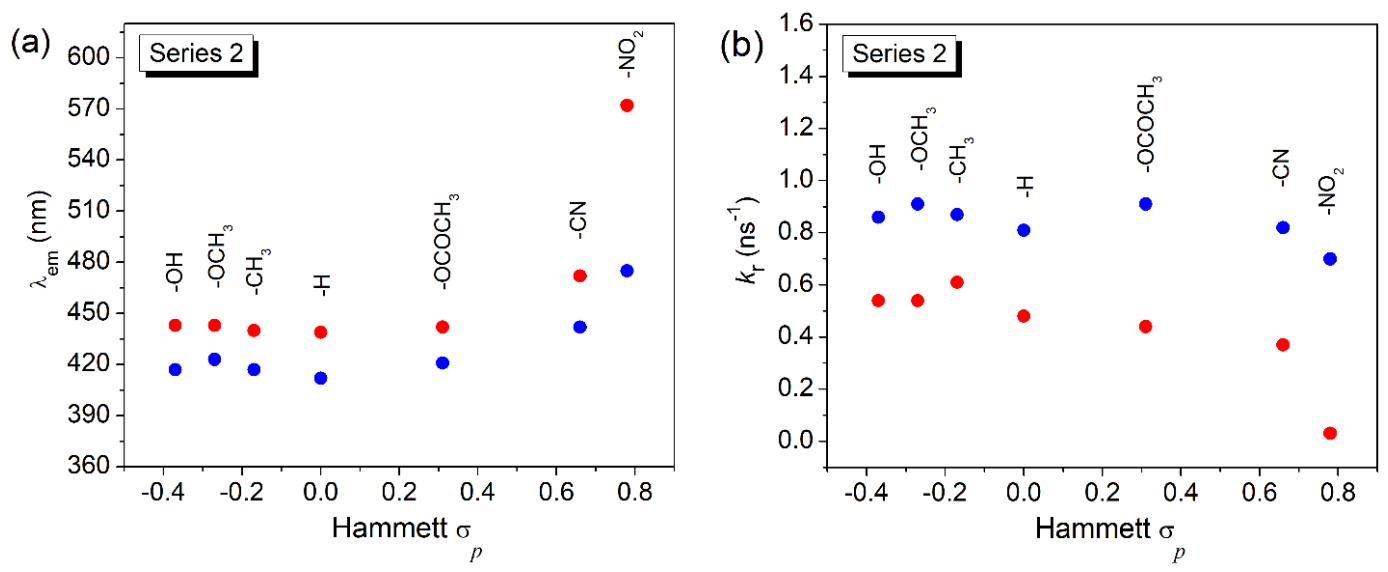

Figure 9. Experimental data (red) and computational calculations (blue) for the emission properties of DSBs-series 2 in $\mathrm{CHCl}_{3}$ as a function of the corresponding $\sigma_{p}$ : (a) $\lambda_{\mathrm{em}}$ (b) $k_{\mathrm{r}}$.

Results in Figures 8 and 9, along with the emission spectra in Figures 7, show that in $\mathrm{CHCl}_{3}$ the ED and EW groups of the substituted DSB structures lead to a bathochromic shift of the emission band, which is greater in the case of EW groups. This agrees with the results from absorption spectroscopy. Additionally, we measure the fluorescence lifetimes $(\tau)$ for all DSBs under $\mathrm{N}_{2}$. However, in this case there seems to be no correlation between the values obtained and the electronic nature of the substituents (Tables S3-S4). 
As shown before, we correlate the experimental and the calculated values to determine how well this computational model can predict the emission properties of the DSBs of series 1 and 2 (Figure 10). From this figure we can see an excellent correlation among the $\lambda_{\text {em }}^{c a l}$ and $\lambda_{\text {em }}^{e x p}$ values $(r=0.95)$, although the absolute emission wavelength values are about $35 \mathrm{~nm}$ shorter than the experimental values. The computational method correctly predicts that the emission wavelengths of DSBs of

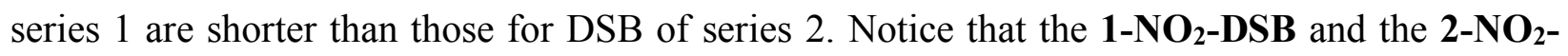
DSB were excluded from the linear regression presented, due to their particular emission behavior and photophysics that may result in unusual behavior for this moiety. This explains the difference in the Stokes shifts, while for the other DSBs the difference between the calculated and experimental Stokes shifts is not greater than $11 \mathrm{~nm}$, for the nitro derivatives the experimental values are $\sim 70 \mathrm{~nm}$ above the calculated ones (see Stoke shifts in Table S5). Thus, the calculations correctly predict that including the nitro group leads to the largest red shift but underestimate the effect of the geometry relaxation in the excited state, and consequently, the calculated emission wavelength is too short compared to the experimental value. The Pearson's $r$ value for the correlation in Figure 10a including the $\mathbf{N O}_{2}$-DSBs is 0.88 . On the other hand, Figure 10b compares the $k_{r}^{\text {exp }}$ and the $k_{r}^{c a l}$ values. This figure reveals a good correlation between these quantities (Pearson's $\mathrm{r}=0.72$ for DSBs-series 1 and 0.85 for DSBs-series 2), although it is not high enough for quantitative predictions. It was observed that the computational method correctly clusters the high values of $k_{\mathrm{r}}$ for DSBs of series 1 , which experimentally are associated to low values of $\tau$ (see equation 6), and the low values of $k_{\mathrm{r}}$ for DSBs of series 2 experimentally associated to high values of $\tau$. 

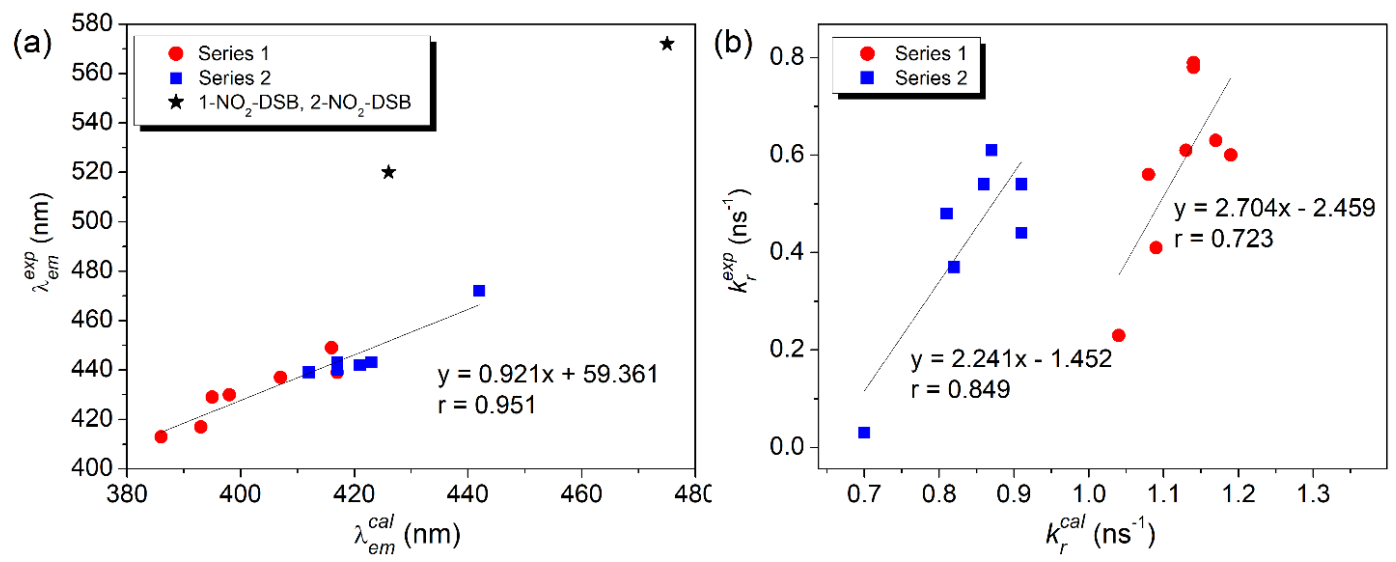

Figure 10: Comparison of experimental and calculated emission properties (a) $\lambda_{e m}^{\text {exp }}$ and $\lambda_{e m}^{c a l}$, (b) $k_{r}^{\text {exp }}$ and $k_{r}^{c a l}$. Red circles: DSBs of series 1. Blue squares: DSBs of series 2. Black stars: 1-NO2-DSB and 2$\mathbf{N O}_{2}$-DSB, which are considered as outliers.

In general, the correlation found between experimental and calculated properties shows that TDDFT calculations are an excellent tool to predict structure-property relationships, and they can be useful to approximate the properties not only for DSBs but also for their polymeric analogs, which are usually difficult to determine by experimental methods. Thus, this work also makes a valuable contribution by presenting computational chemistry as an alternative to study conjugated organic materials.

Finally, we analyzed the calculated geometries of the DSBs and found that their geometries significantly change upon excitation and that these changes are similar for all molecules. The most significant changes occur in the $\mathrm{C}-\mathrm{C}$ bond distances which are presented in Figure 11. We observe that the largest change occurs in the vinyl moiety, where the single bonds contract and the double bonds elongate, and that the changes in the central aromatic ring are larger than in the terminal ones. These geometry changes are coupled to the electron density changes presented in Figure 5, as a density increase upon excitation results in a shorter $\mathrm{C}-\mathrm{C}$ bond and a density decrease in a 
longer $\mathrm{C}-\mathrm{C}$ bond. The fact that the geometric changes are very similar between the different DSB is consistent with the observation that the Stokes shifts are constant across all the molecules.

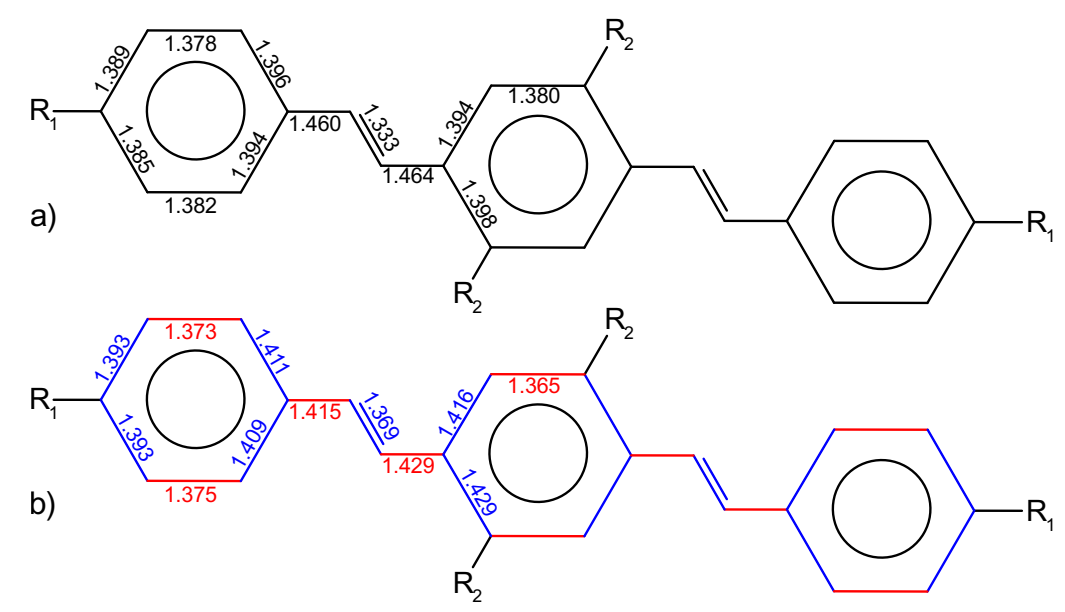

Figure 11: Calculated average $\mathrm{C}-\mathrm{C}$ bond lengths in the ground state (a) and in the excited state (b). Bonds lengths that decrease upon excitation are shown in red and those that increase in blue. The standard deviation of each C-C bond length is $\leq 0.005 \AA$.

\section{Conclusions}

The structure-property relationships of fifteen model DSBs were studied by spectroscopic (UVvis and FL) techniques and TDDFT computational method. In both cases, it was observed that the ED groups studied have a moderate effect on the bathochromic shift of the absorption and emission bands, whereas the presence of EW groups produces larger shifts. Additionally, the presence of two methoxy groups on the central ring enhances the effect. This was attributed to the substituents changing the orbital energies leading to the reduction of the band gap energies. Thus, ED groups increase the HOMO and LUMO energies, affecting more the HOMO, and the EW groups decrease the energies of both HOMO and LUMO, but their effect on the LUMO is larger.

Good correlations were found between the $\lambda_{a b s}^{c a l}$ and $\lambda_{a b s}^{\exp }$ values (Pearson's $\mathrm{r}=0.99$ ) and the $\lambda_{e m}^{c a l}$ and $\lambda_{e m}^{\text {exp }}$ values (Pearson's $\mathrm{r}=0.95$ ). The computational method correctly predicts the peak 
position for the single transition of DSBs of series 1 and for both transitions of DSBs of series 2 and that the emission wavelengths of DSBs of series 1 are shorter than those for DSBs of series 2. Excellent correlations were found also between the $\Delta \mathrm{E}_{a b s}^{c a l}$ and $\Delta \mathrm{E}_{a b s}^{\text {exp }}$ (Pearson's $\mathrm{r}=0.99$ ). The computational method correctly predicts that the energy gaps for DSBs of series 1 are larger than those for DSBs of series 2. Good agreements were found between the $F_{\text {osc }}^{c a l}$ and $F_{\text {osc }}^{\text {exp }}$ values (Pearson's $r=0.87$ ). Although not high enough for quantitative predictions, the theoretical method correctly clusters the transitions of DSBs of series 1 as the most intense and the second transitions of DSBs of series 2 as the least.

Distyrylbenzene motifs are important in many polymeric systems with applications in molecular electronics, electroluminescent devices, OLEDs and optocouplers. However, the intimate understanding of these chromophores in the polymers used for advanced optoelectronic applications is hindered by the intrinsic properties of the polymer, including aggregation phenomena, energy migration and limited solubility. The molecules reported here offer the opportunity for a detailed understanding of these key distyrylbenzene moieties from both an experimental and computational point of view. Thus, this study shows that the DSB systems possess valuable optoelectronic properties, which can be adjusted with the inclusion of substituents with strongly ED and/or EW nature. The study of the structure-property relationships by computational techniques helps us to choose properly the structures that will be most appropriate and efficient for the desired applications.

\section{AUTHOR INFORMATION}

\section{Corresponding Author}

* Email: Dr. Cesar A. Sierra (casierraa@unal.edu.co) and Dr. Juan C. Scaiano (titoscaiano@mac.com). 


\section{Author Contributions}

¿These authors equally contributed to this work. The manuscript was written through the contributions of all authors. All authors have given approval to the final version of the manuscript.

\section{Acknowledgment}

We thank the Administrative Department of Science, Technology, and Innovation (COLCIENCIAS) through the projects No. 534-2011 and 608-2011, the Natural Sciences and Engineering Research Council of Canada, the Canada Foundation for Innovation, and the Canada Research Chairs Program.

\section{References}

1. Hörhold, V. H.-H.; Opfermann, J., Poly-P-Xylyliden. Synthesen Und Beziehungen Zwischen Struktur Und Elektrophysikalischen Eigenschaften. Makromol. Chem. 1970, 131, 105132.

2. Burroughes, J. H.; Bradley, D. D. C.; Brown, A. R.; Marks, R. N.; Mackay, K.; Friend, R. H.; Burns, P. L.; Holmes, A. B., Light-Emitting Diodes Based on Conjugated Polymers. Nature 1990, 347, 539-541.

3. Grimsdale, A. C.; Leok Chan, K.; Martin, R. E.; Jokisz, P. G.; Holmes, A. B., Synthesis of Light-Emitting Conjugated Polymers for Applications in Electroluminescent Devices. Chem. Rev. 2009, 109, 897-1091.

4. He, Y.; Cheng, N.; Xu, X.; Fu, J.; Wang, J.-a., A High Efficiency Pure Organic Room Temperature Phosphorescence Polymer PPV Derivative for OLED. Org. Electron. 2019, 64, 247251.

5. Al-Asbahi, B. A., Influence of $\mathrm{SiO}_{2} / \mathrm{TiO}_{2}$ Nanocomposite on the Optoelectronic Properties of PFO/MEH-PPV-Based OLED Devices. Polymers 2018, 10, 800.

6. Chen, L.; Jia, W.; Lan, Z.; Tang, X.; Zhu, F.; Xiong, Z., Tuning the Polarity of Organic Magnetic Field Effects in Polymer Light-Emitting Diodes by Incorporating a Colloidal Quantum Dots Thin Layer. Org. Electron. 2018, 55, 165-169.

7. Chitraningrum, N.; Chu, T.-Y.; Huang, P.-T.; Wen, T.-C.; Guo, T.-F., The Triplet-Triplet Annihilation Process of Triplet to Singlet Excitons to Fluorescence in Polymer Light-Emitting Diodes. Org. Electron. 2018, 62, 505-510.

8. Farjamtalab, I.; Sabbaghi-Nadooshan, R., Current Density of Anodes, Recombination Rate and Luminance in MEH-PPV, Mdmo-PPV, and P3HT Polymers in Polymer Light-Emitting Diodes. Polym. Sci., Ser. A 2016, 58, 726-731.

9. Hassan, M. U.; Liu, Y.-C.; Yetisen, A. K.; Butt, H.; Friend, R. H., Energy Landscape of Vertically Anisotropic Polymer Blend Films toward Highly Efficient Polymer Light-Emitting Diodes (PLEDs). Adv. Funct. Mater. 2018, 28, 1705903. 
10. Huang, T.-H.; Chi, X.-C.; Xu, T.-N.; Zhang, J.-R.; Xu, H.-Y.; Zhu, Z.-Y.; Yu, R.-B.; Wang, Y.-H.; Zhang, H.-Z., Effect of Ag Nanoparticles on the Photoluminescence of Poly[2-Methoxy-5(2-Ethylhexyloxy)-1,4-Phenylene-Vinylene]. J. Photochem. Photobiol. A. Chem. 2018, 356, 334339.

11. Rezaie, M. N.; Manavizadeh, N.; Nayeri, F. D.; Bidgoli, M. M.; Nadimi, E.; Boroumand, F. A., Effect of Seed Layers on Low-Temperature, Chemical Bath Deposited ZnO NanorodsBased near UV-OLED Performance. Ceram. Int. 2018, 44, 4937-4945.

12. Ribierre, J.-C., et al., A Solvent-Free and Vacuum-Free Melt-Processing Method to Fabricate Organic Semiconducting Layers with Large Crystal Size for Organic Electronic Applications. J. Mater. Chem. C 2019, 7, 3190-3198.

13. Rörich, I.; Schönbein, A.-K.; Mangalore, D. K.; Halda Ribeiro, A.; Kasparek, C.; Bauer, C.; Crăciun, N. I.; Blom, P. W. M.; Ramanan, C., Temperature Dependence of the Photo- and Electroluminescence of Poly(p-phenylene vinylene) Based Polymers. J. Mater. Chem. C 2018, 6, 10569-10579.

14. McGehee, M. D.; Heeger, A. J., Semiconducting (Conjugated) Polymers as Materials for Solid-State Lasers. Adv. Mater. 2000, 12, 1655-1668.

15. Laureto, E.; da Silva, M. A. T.; Fernandes, R. V.; Duarte, J. L.; Dias, I. F. L.; de Santana, H.; Marletta, A., Laser Irradiation Effects on the Optical Properties of Layer-by-Layer PPV/Congo Red Thin Films. Synth. Met. 2011, 161, 87-91.

16. Liu, M.; Liu, Y.; Peng, Z.; Mu, Q.; Cao, Z.; Lu, X.; Ma, J.; Xuan, L., Ultra-Broad Range Organic Solid-State Laser from a Dye-Doped Holographic Grating Quasi-Waveguide Configuration. J. Phys. D 2017, 50, 315103.

17. Cheng, Y.-J.; Yang, S.-H.; Hsu, C.-S., Synthesis of Conjugated Polymers for Organic Solar Cell Applications. Chem. Rev. 2009, 109, 5868-5923.

18. Hagemann, O.; Jørgensen, M.; Krebs, F. C., Synthesis of an All-in-One Molecule (for Organic Solar Cells). J. Org. Chem. 2006, 71, 5546-5559.

19. Alam, S., et al., Organic Solar Cells Based on Anthracene-Containing PPE-PPVs and NonFullerene Acceptors. Chem. Pap. 2018, 72, 1769-1778.

20. Lim, K.-G.; Park, J.-M.; Mangold, H.; Laquai, F.; Choi, T.-L.; Lee, T.-W., Bimolecular Crystals with an Intercalated Structure Improve Poly(p-phenylenevinylene)-Based Organic Photovoltaic Cells. ChemSusChem 2015, 8, 337-344.

21. Mansha, M.; Khan, I.; Ullah, N.; Qurashi, A., Synthesis, Characterization and VisibleLight-Driven Photoelectrochemical Hydrogen Evolution Reaction of Carbazole-Containing Conjugated Polymers. Int. J. Hydrog. Energy 2017, 42, 10952-10961.

22. Mustapha, N.; Fekkai, Z.; Alkaoud, A., Enhanced Efficiency of Organic Solar Cells Based on (MEH-PPV) with Graphene and Quantum Dots. Optik 2016, 127, 2755-2760.

23. Yue, W.; Sun, W.; Wang, S.; Zhang, G.; Lan, M.; Nie, G., Influence of Photoactive Layer Structure on Device Performance of Poly(2-Methoxy-5-(2-Ethylhexyloxy)-1,4-Phenylene Vinylene)-CuInS 2 /ZnO Solar Cells. J. Nanosci. Nanotechnol. 2015, 15, 4421-4425.

24. Thomas, S. W.; Joly, G. D.; Swager, T. M., Chemical Sensors Based on Amplifying Fluorescent Conjugated Polymers. Chem. Rev. 2007, 107, 1339-1386.

25. Feng, X.; Feng, F.; Yu, M.; He, F.; Xu, Q.; Tang, H.; Wang, S.; Li, Y.; Zhu, D., Synthesis of a New Water-Soluble Oligo(Phenylenevinylene) Containing a Tyrosine Moiety for Tyrosinase Activity Detection. Org. Lett. 2008, 10, 5369-5372.

26. Bai, H.; Yuan, H.; Nie, C.; Wang, B.; Lv, F.; Liu, L.; Wang, S., A Supramolecular Antibiotic Switch for Antibacterial Regulation. Angew. Chem. Int. Ed. 2015, 54, 13208-13213. 
27. Yu, C.-Y.; Chen, P.-Y.; Lin, Y.-H.; Ciou, P.-J., Synthesis and Characterization of Alternating Copolymers Containing Bipyridine and Phenylene Vinylene for Fluorescent Chemosensors. J. Appl. Polym. Sci. 2015, 132, 42795.

28. Zhou, N.; Wang, L.; Thompson, D. W.; Zhao, Y., OPE/OPV H-mers: Synthesis, Electronic Properties, and Spectroscopic Responses to Binding with Transition Metal Ions. Tetrahedron 2011, 67, 125-143.

29. Zhu, C.; Yang, Q.; Liu, L.; Wang, S., A Potent Fluorescent Probe for the Detection of Cell Apoptosis. Chem. Comm. 2011, 47, 5524-5526.

30. White, K. A.; Chengelis, D. A.; Zeller, M.; Geib, S. J.; Szakos, J.; Petoud, S.; Rosi, N. L., Near-Infrared Emitting Ytterbium Metal-Organic Frameworks with Tunable Excitation Properties. Chem. Comm. 2009, 0, 4506-4508.

31. White, K. A.; Chengelis, D. A.; Gogick, K. A.; Stehman, J.; Rosi, N. L.; Petoud, S., NearInfrared Luminescent Lanthanide MOF Barcodes. J. Am. Chem. Soc. 2009, 131, 18069-18071.

32. Wang, J.; Zhang, Y.; Ye, F.; Liu, X.; Wang, X.; Zhou, X.; Lu, Y., Enhancement of Orientation of Rigid Polymer Blocks by Incorporating Rod-Coil Block Copolymer Chains into Metal-Organic Frameworks. Polym Int. 2019, 68, 772-778.

33. Precup-Blaga, F. S.; Garcia-Martinez, J. C.; Schenning, A. P. H. J.; Meijer, E. W., Highly Emissive Supramolecular Oligo(p-phenylene vinylene) Dendrimers. J. Am. Chem. Soc. 2003, 125, 12953-12960.

34. Ding, L.; Chang, D.; Dai, L.; Ji, T.; Li, S.; Lu, J.; Tao, Y.; Delozier, D.; Connell, J., Luminescent Dendrons with Oligo(Phenylenevinylene) Core Branches and Oligo(Ethylene Oxide) Terminal Chains. Macromolecules 2005, 38, 9389-9392.

35. Kim, E.; Lee, J.; Ahn, T., Synthesis and Light-Emitting Properties of a Fluorene Containing Hyperbranched Conjugated Poly(Phenylene Vinylene). Mol. Cryst. Liq. Cryst. 2016, 636, 73-79.

36. Organista-Mateos, U.; Martínez-Klimov, M. E.; Pedro-Hernández, L. D.; Borja-Miranda, A.; Cortez-Maya, S.; Hernández-Ortega, S.; Martínez-García, M., Synthesis of Porphyrin Dendrimers Via Heck Reaction and Their Photovoltaic Properties. J. Photochem. Photobiol. A. Chem. 2017, 343, 58-65.

37. Muktha, B.; Madras, G.; Guru Row, T. N.; Scherf, U.; Patil, S., Conjugated Polymers for Photocatalysis. J. Phys. Chem. B 2007, 111, 7994-7998.

38. Nielsen, C. B.; Johnsen, M.; Arnbjerg, J.; Pittelkow, M.; McIlroy, S. P.; Ogilby, P. R.; Jørgensen, M., Synthesis and Characterization of Water-Soluble Phenylene-Vinylene-Based Singlet Oxygen Sensitizers for Two-Photon Excitation. J. Org. Chem. 2005, 70, 7065-7079.

39. Liu, S.; Yuan, H.; Bai, H.; Zhang, P.; Lv, F.; Liu, L.; Dai, Z.; Bao, J.; Wang, S., Electrochemiluminescence for Electric-Driven Antibacterial Therapeutics. J. Am. Chem. Soc. 2018, 140, 2284-2291.

40. Martin, R. E.; Diederich, F., Linear Monodisperse П-Conjugated Oligomers: Model Compounds for Polymers and More. Angew. Chem. Int. Ed. 1999, 38, 1350-1377.

41. Cárdenas, J. C.; Ochoa-Puentes, C.; Sierra, C. A., Phenylenevinylene Systems: The Oligomer Approach. In Conducting Polymers, Yilmaz, F., Ed. InTech: Rijeka, 2016; p Ch. 10.

42. Heller, A., Organic Liquid Scintillators. Vi. Substituted Distyrylbenzenes: Scintillation Properties and Spectra of Absorption and Fluorescence. J. Chem. Phys. 1964, 40, 2839-2851.

43. Patel, K. N.; Bedekar, A. V., One-Pot Synthesis and Study of Spectroscopic Properties of Oligo(phenylenevinylene)s. Tetrahedron Lett. 2015, 56, 6617-6621.

44. Wu, F.; Tian, W.; Sun, J.; Shen, J.; Pan, X.; Su, Z., Study on the Electronic Structure of Phenylene Vinylene Dimers with Different Substituents. Mater. Sci. Eng. B 2001, 85, 165-168. 
45. Chaieb, A.; Khoukh, A.; Brown, R.; François, J.; Dagron-Lartigau, C., Characterization of Model Luminescent PPV Analogues with Donating or Withdrawing Groups. Opt. Mater. 2007, 30, 318-327.

46. Laughlin, B. J.; Duniho, T. L.; El Homsi, S. J.; Levy, B. E.; Deligonul, N.; Gaffen, J. R.; Protasiewicz, J. D.; Tennyson, A. G.; Smith, R. C., Comparison of 1,4-Distyrylfluorene and 1,4Distyrylbenzene Analogues: Synthesis, Structure, Electrochemistry and Photophysics. Org. Biomol. Chem. 2013, 11, 5425-5434.

47. Gao, F.; Liao, Q.; Xu, Z.-Z.; Yue, Y.-H.; Wang, Q.; Zhang, H.-L.; Fu, H.-B., Strong TwoPhoton Excited Fluorescence and Stimulated Emission from an Organic Single Crystal of an Oligo(Phenylene Vinylene). Angew. Chem. Int. Ed. 2010, 49, 732-735.

48. Kim, M.; Whang, D. R.; Gierschner, J.; Park, S. Y., A Distyrylbenzene Based Highly Efficient Deep Red/near-Infrared Emitting Organic Solid. J. Mater. Chem. C 2015, 3, 231-234.

49. Nielsen, C. B.; Arnbjerg, J.; Johnsen, M.; Jorgensen, M.; Ogilby, P. R., Molecular Tuning of Phenylene-Vinylene Derivatives for Two-Photon Photosensitized Singlet Oxygen Production. J. Org. Chem. 2009, 74, 9094-9104.

50. Chen, X.; Bai, F.-Q.; Wang, H.-T.; Zhang, H.-X.; Tang, Y., The Impact of Molecular Stacking Interactions on the Electronic Structure and Charge Transport Properties in Distyrylbenzene (DSB-) Based D-A Complexes: A Theoretical Study. $R S C A d v$. 2015, 5, 4768147691.

51. Nayyar, I. H.; Masunov, A. E.; Tretiak, S., Comparison of TD-DFT Methods for the Calculation of Two-Photon Absorption Spectra of Oligophenylvinylenes. J. Phys. Chem. C 2013, $117,18170-18189$.

52. Oliveira, E. F.; Shi, J.; Lavarda, F. C.; Luer, L.; Milian-Medina, B.; Gierschner, J., Excited State Absorption Spectra of Dissolved and Aggregated Distyrylbenzene: A TD-DFT State and Vibronic Analysis. J. Chem. Phys. 2017, 147, 4993216.

53. Sancho-García, J. C., et al., Theoretical Characterization and Design of End-Substituted Distyrylbenzenes as Excitation Shuttles in One-Dimensional Channels. Adv. Mater. 2004, 16, 1193-1197.

54. Wang, B.-C.; Chang, J.-C.; Pan, J.-H.; Xue, C.; Luo, F.-T., Theoretical Investigation of Electroluminescent Material 1,4-Distyrylbenzene Derivatives. J. Mol. Struct. THEOCHEM 2003, 636, 81-87.

55. Wang, H.-W.; Chen, C.; Hsu, F.-C.; Shieh, H.-C.; Wang, J. K.; Lin, S. H.; Hayashi, M., Theoretical Studies of Distyrylbenzene and Its Optical Properties. J. Chin. Chem. Soc. 2005, 52, 665-675.

56. Estrada, S. E.; Ochoa-Puentes, C.; Sierra, C. A., Phenylenevinylene Oligomers by Mizoroki-Heck Cross Coupling Reaction. Structural and Optoelectronic Characterization. J. Mol. Struct. 2017, 1133, 448-457.

57. Wang, F.; He, F.; Xie, Z. Q.; Li, Y. P.; Hanif, M.; Li, M.; Ma, Y., Poly(p-phenylene vinylene) Derivatives with Different Contents of cis-Olefins and Their Effect on the Optical Properties. Macromol. Chem. Phys. 2008, 209, 1381-1388.

58. Cárdenas, J. C.; Ochoa-Puentes, C.; Gutiérrez-Puebla, E.; Sierra, C. A., Synthesis, Crystal Structure Determination and Photoluminescence Properties of a Pure Anti Trans-Trans Phenylenevinylene Derivative. Synth. Met. 2016, 215, 194-199.

59. Qi, Z.; Wei, B.; Sun, Y.; Wang, X.; Kang, F.; Hong, M.; Tang, L., Comparative Study of Photoelectric Properties of Regiosymmetrical Poly(3,4-dialkoxythiophene)s. Polym. Bull. 2011, $66,905-915$.

60. Wang, Y.; Suna, A.; Mahler, W.; Kasowski, R., Pbs in Polymers. From Molecules to Bulk Solids. J. Chem. Phys. 1987, 87, 7315-7322. 
61. Kawauchi, S.; Antonov, L.; Okuno, Y., Prediction of the Color of Dyes by Using TimeDependent Density Functional Theory (TD-DFT). Bulg. Chem. Commun. 2014, 46, 228-237.

62. Brouwer Albert, M., Standards for Photoluminescence Quantum Yield Measurements in Solution (Iupac Technical Report). In Pure Appl. Chem., 2011; Vol. 83, p 2213.

63. Savarese, M.; Aliberti, A.; De Santo, I.; Battista, E.; Causa, F.; Netti, P. A.; Rega, N., Fluorescence Lifetimes and Quantum Yields of Rhodamine Derivatives: New Insights from Theory and Experiment. J. Phys. Chem. A 2012, 116, 7491-7497.

64. Yanai, T.; Tew, D. P.; Handy, N. C., A New Hybrid Exchange-Correlation Functional Using the Coulomb-Attenuating Method (CAM-B3LYP). Chem. Phys. Lett. 2004, 393, 51-57.

65. Weigend, F.; Ahlrichs, R., Balanced Basis Sets of Split Valence, Triple Zeta Valence and Quadruple Zeta Valence Quality for H to Rn: Design and Assessment of Accuracy. Phys. Chem. Chem. Phys. 2005, 7, 3297-3305.

66. Weigend, F., Accurate Coulomb-Fitting Basis Sets for H to Rn. Phys. Chem. Chem. Phys. 2006, 8, 1057-1065.

67. Cossi, M.; Rega, N.; Scalmani, G.; Barone, V., Energies, Structures, and Electronic Properties of Molecules in Solution with the C-PCM Solvation Model. J. Comput. Chem. 2003, 24, 669-681.

68. Neese, F., The Orca Program System. Wiley Interdiscip. Rev. Comput. Mol. Sci. 2012, 2, 73-78.

69. Neese, F.; Wennmohs, F.; Hansen, A.; Becker, U., Efficient, Approximate and Parallel Hartree-Fock and Hybrid Dft Calculations. A 'Chain-of-Spheres' Algorithm for the Hartree-Fock Exchange. Chem. Phys. 2009, 356, 98-109.

70. Hirata, S.; Head-Gordon, M., Time-Dependent Density Functional Theory within the Tamm-Dancoff Approximation. Chem. Phys. Lett. 1999, 314, 291-299.

71. Nienhuis, G.; Alkemade, C. T. J., Atomic Radiative Transition Probabilities in a Continuous Medium. Physica $B+C$ 1976, 81, 181-188.

72. Hansch, C.; Leo, A.; Taft, R. W., A Survey of Hammett Substituent Constants and Resonance and Field Parameters. Chem. Rev. 1991, 91, 165-195. 